\title{
Wildland Fires Statistics In The Canton Santa Ana, Province Of Manabí, Ecuador, In The Period 2012 - 2018
}

\author{
Marcos Pedro Ramos-Rodríguez ${ }^{1}$, Humberto Josué García-Castro ${ }^{2}$, Antonio Carlos Batista ${ }^{3}$, Alexandre \\ França Tetto $^{4}$, Ronaldo Viana Soares ${ }^{5}$, \& Ignacio Estévez Valdés 6
}

\footnotetext{
${ }^{1}$ Universidad Estatal del Sur de Manabí, Ecuador.

${ }^{2}$ Cuerpo de Bomberos de Portoviejo, Manabí, Ecuador.

${ }^{3}$ Universidad Federal de Paraná, Brasil.

${ }^{4}$ Universidad Federal de Paraná, Brasil.

${ }^{5}$ Universidad Federal de Paraná, Brasil.

${ }^{6}$ Universidad Estatal del Sur de Manabí, Ecuador.

E-mails: marcos.ramos@unesum.edu.ec,josuegar1995@hotmail.com, batistaufpr@ufpr.br, tetto@ufpr.br, rvsoares@ufpr.br, ignacioestevez57@gmail.com
}

\begin{abstract}
The analysis of wildland fires statistics provides essential information for the development of effective fire management programs in the communities. These analyzes allow to define where, when and why fires occur. The objective of this work was to analyze the wildland fires statistics in the Canton of Santa Ana, province of Manabí, Ecuador, during the period 2012 - January 2018. Before this period, there are no statistics of this type of fires in the Fire Department of Santa Ana, institution that provided this information. In the area under study, weeds and crop residues predominate, mainly corn, and some pastures. The analysis was made considering the occurrences of fires in a spatiotemporal context (years, months, days of the week and type of vegetation affected). Statistical analyzes were performed with the SPSS v.22 (Statistical Package for the Social Sciences), working with a significance level of 0.05 . In the analyzed period, 91 occurrences were reported, corresponding to 2016 the highest percentage (38.46\%) which represents 35 fires, followed by 2017 with 16. Between September and January, 87.91\% of the total occurrences were registered, which is associated to the time of greater use of fire by the peasants to clean the land and with little rainfall. The largest number of fires were reported in weeds. No statistically significant difference was found for the occurrences according to the days of the week $(\mathrm{p}=0.763)$ and the hours in which occurrences were reported $(\mathrm{p}=0.139)$ according to the Kruskal-Wallis statistical test. It could be concluded that more than half of the fires occurred in the Ayacucho Parish, associated with the greater number of areas of agricultural crops. It was also found that the logs lack important information to make these analyzes with the required quality. Among these information may be mentioned: burned area, coordinates, causes, conditions of danger, type of fire, means used in the extinction and data on vegetation, which have been included in a proposed fire report.
\end{abstract}

Keywords: Forest fires, fire prevention, historical behavior, forest protection, vegetation fire records. 